\title{
Modelling and Simulation Studies of Multiple Packings Distillation Column
}

\author{
Sabha M. Almanie \\ Abdullah M. O. Albloshi \\ Mallak Alhosni \\ Shahad Al-Mighaizwi \\ Jimoh K. Adewole
}

\author{
International Maritime College Oman \\ International Maritime College Oman \\ International Maritime College Oman \\ International Maritime College Oman \\ International Maritime College Oman
}

\begin{abstract}
Large scale separation of liquid mixtures into their various components is one of the major operations in the process industries. Distillation remains one of the predominant separation techniques that is use for these separations. It accounts for about $90 \%$ of product recovery and purification in the process industries. The strength of the distillation technique lies on its simplicity, low capital investment, and low risk as compared to other traditional separation techniques. In the present study, the synergistic effects of multiple packings in binary distillation column operations was investigated. The investigation was done using Aspen HYSYS process simulation software. Specifically, the study was done to establish a packing order that will be required to achieve a reduction in energy consumption and the overall cost of separation processes that involve distillation operation. The packed distillation was simulated using Berl saddles, Intalox saddles, and Pall rings as the column internals. Single, dual and triple packing arrangements were evaluated. The multiple packing arrangement investigated were Berl/Intalox, Berl/Pall, Pall/Intalox, and Berl/Intalox/Pall. Binary mixtures of pentane and hexane was used as feed to the column. The results of this simulation revealed that the use of multiple packing arrangement had a significant effect on the energy consumption, the height of packing and hence the cost of equipment fabrication. For instance, the estimated cost of packings (USD) are 524.89 for Berl, 406.85 for Pall, 303.77 for Intallox, 427.09 for Berl/Intalox, 473.06 for Berl/Pall, 323.51 for Pall/Intalox, and 388.60 for Berl/Intalox/Pall. These results clearly revealed that multiple packing arrangements can be used to reduce the cost of column fabrication without compromising the performance of the equipment.
\end{abstract}

\section{Introduction}

Distillation is one of the separation techniques used to separate the basic components from a mixture. It is a process which involves the conversion of a liquid into vapour which is subsequently condensed back and collected in liquid form (Gregersen, 2016). Series of trays or packing are commonly used to provide much contact between the vapour and liquid. In distillation, the separation is based on the individual boiling point or relative volatility of the constituent components of the mixture (Jin, Ruan, Cheng, \& Lü, 2011). Basically, the distillation column can be divided into two main sections which are rectifying section and striping section (S. Moran, 2017).

The rectifying section consists of overhead condenser and reflux line. Moreover, it is located above the feed tray and it has a higher concentration of light component than the striping section. On the other hand, the striping section, which is located below the feed tray, involves of bottom product and the reboiler. The hot feed drops from the feed tray to the lower trays. It heats and strips the lighter components while the heavier components flow to the bottom of the tower. The distillation column can be classified, based on the internals, into plate or packed column (Olujić, 2014). Plate column includes such types of trays like bubble-cap, sieve and valve tray.

The second of the distillation column is packed distillation column. Both types of internals are 


\section{Journal of Student Research}

Fourth Middle East College Student Research Conference, Muscat, Sultanate of Oman

essential to provide more surface area between the evaporating materials from the reboiler and the condensed liquid from the trays. The work presented therein is based on the packed column. There are three types of packings in distillation column. They include random, structured and stacked packing. Random packing consists of pieces that are randomly dumped into a packed column. Structured packing involves packing pieces which have specific geometric shapes.

Stacked packing has uniformly arranged packings inside the distillation. Packing materials can be made of metals, ceramics or polymers. Some examples of packing materials include Rasching ring, Pall ring, Intalox saddle, and Berl saddle (Sölken, 2008).

The objective of this research is to simulate a packed distillation column with multiple packing arrangements and then evaluate its performance.

\section{Methodology}

In this work, the Aspen HYSYS simulation software was used for simulating a packed distillation column. The feed used is a mixture of pentane and hexane. The molar compositions and the flow rates of the feed and the top products were specified as follows:

\begin{tabular}{|l|l|l|}
\hline Composition & Pentane & Hexane \\
\hline Distillate & 0.98 & 0.02 \\
\hline Bottom & 0.05 & 0.95 \\
\hline
\end{tabular}

Table 1. Compositions used for the simulation

Feed composition: $\$ \mathrm{x}_{-} \mathrm{F}=0.47 \$$

Feed flowrate: $\$(\mathrm{~F})=10 \backslash ; \mathrm{kgmol} / \mathrm{hr} \$$

The vapor liquid equilibrium curves for binary mixtures of pentane - hexane were obtained using vapor pressure values estimated from data and correlations of Design Institute for Physical Property, New York and Thermodynamics Research Centre, Texas, USA provided in HYSYS and PRO II. Details of how this was obtained is provided elsewhere (Adewole, 2009). The fluid-package used is the Peng - Robinson thermodynamics model. It was assumed that cooling water is available at $90^{\circ} \mathrm{F}\left(32.22^{\circ} \mathrm{C}\right)$ and sufficient to $\mathrm{cool}$ and condense a vapor to $120^{\circ} \mathrm{F}\left(49^{\circ} \mathrm{C}\right)$.

Vapor Fraction $\$\left(v_{-} f\right)=0.00 \$$

The distillation column was simulated using the number of stages, operating pressure and temperature, reflux ratios, and the flow rates as obtained from literature (Adewole, 2009). The column was first converged with the specifications from the simulation basis shown in the table below:

\begin{tabular}{|l|l|}
\hline Feed & Mixture of Pentane and Hexane \\
\hline Feed flow rate & $10 \mathrm{kmol} / \mathrm{h}$ \\
\hline Feed Composition & $47 \%$ Pentane \\
\hline Feed Temperature & $80.11^{\circ} \mathrm{C}$ \\
\hline Feed Pressure & $245 \mathrm{KPa}$ \\
\hline Temperature of cooling water in & $32^{\circ} \mathrm{C}$ \\
\hline Temperature of cooling water out & $49^{\circ} \mathrm{C}$ \\
\hline Total Number of Theoretical Plate & 9 (Top to bottom, reboiler and condenser exclusive) \\
\hline Condenser Pressure & $206.8 \mathrm{KPa}$ \\
\hline Reboiler Pressure & $275.8 \mathrm{KPa}$ \\
\hline Distillate Rate & $4.5161 \mathrm{kmol} / \mathrm{hr}$ \\
\hline
\end{tabular}


Journal of Student Research

Fourth Middle East College Student Research Conference, Muscat, Sultanate of Oman

\begin{tabular}{|l|l|}
\hline Bottom Rate & $5.4839 \mathrm{kmol} / \mathrm{h}$ \\
\hline Reflux Ratio & 1.9 \\
\hline Vapour fraction & 0 \\
\hline Packing types & Intalox Saddles, Berl saddles and Pall Rings \\
\hline Fluid Package & Peng Robinson Property Package \\
\hline
\end{tabular}

Table 2. Simulation Basis

The Pall ring, Intalox saddle and Berl saddle were first used individually in the simulation, then a dual combination of the packings were then used. The single, dual as well as the multiple packing simulations were carried out using the Tray Sizing Utilities of the simulation software. Appropriate packing type, size, height and arrangement order in the column was selected from AutoSection Information window through the Specs page of the Design tab of the software.

The simulation was then Run again to converge the column, and the results viewed. For dual arrangement, the 'AutoSection' command button was first used to perform the simulation. The initial estimate was then used to perform the multiple simulations by using the "Copy Section" command button and then modify the number of stages as appropriate.

The sizing of the distillation column was done using the approach described in (Adewole, 2009). The flooding velocity is calculated using:

\$\$U_f=Clleft( $\mid$ frac $\{\backslash$ rho_L- $\mid$ rho_V $\}\{\backslash$ rho_V $\} \backslash$ right $)^{\wedge}\{0.5\} \$ \$$

Where, $\$ C=F \_\{S T\} C \_F \$$

The $\$ F_{-}\{\mathrm{ST}\} \$$ is the surface tension factor which is given by:

$\$ \$ F_{-}\{S T\}=\backslash$ left $(\backslash \text { frac }\{\backslash \text { sigma }\}\{20\} \backslash \text { right })^{\wedge}\{0.2\} \$ \$$

Where $\$$ \sigma\$ is the surface tension in dyne/cm.

The \$C_A $\$$ is the flooding capacity factor.

Where $\$ \mathrm{P}_{-} \mathrm{V} \$$ and $\$ \mathrm{P}_{-} \mathrm{L} \$$ are mass densities of vapour and liquid, respectively.

The column diameter (D) was calculated using:

$\$ \$ D=\mid l$ eft $[\backslash \text { frac }\{4 \mathrm{~V}\}\{0.9 \backslash \text { pi|rho_vU }\} \backslash \text { right }]^{\wedge}\{0.5\} \$ \$$

where $\$ \mathrm{~V} \$$ is the flow rate of the vapour and $\$ \mathrm{U} \$$ is the fluid velocity.

For single packing the column height was calculated using the equation:

$\$ \$ Z=$ Numltimes HETP\$ $\$$

For multiple packing, the column height was determined using the equation:

$\$ \$ Z=\mid$ sum_ $\{1\}^{\wedge}\{\mathrm{n}\} \backslash \operatorname{left}($ Num $\mid$ times $\backslash$ HETP\right) $\$ \$$

where $n$ is the number of packed segments filled with a specific packing.

In order to take care of the top vapor disengagement, and the bottom liquid level and reboiler return respectively, the total column diameter is calculated as: 


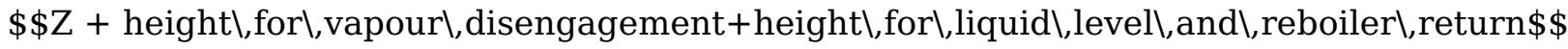

\section{Result and Discussion}

Packed distillation column was simulated using three packing types: Berl Saddles, Intalox Saddles and Pall Rings. The synergistic effect of combining the different types of packing on the performance of the column is shown in the figures below. The performance was evaluated in terms of cost of packing, packed height, mass of packing, flooding and the sectional area.

Starting with judgment that is based on cost, the results obtained are shown in Figure 1. It can be observed that Berl is the most expensive. Moreover, the Pall rings is more expensive than Intalox. It is therefore possible to blend the characteristics of Pall and Intalox to get a cheaper packing material.

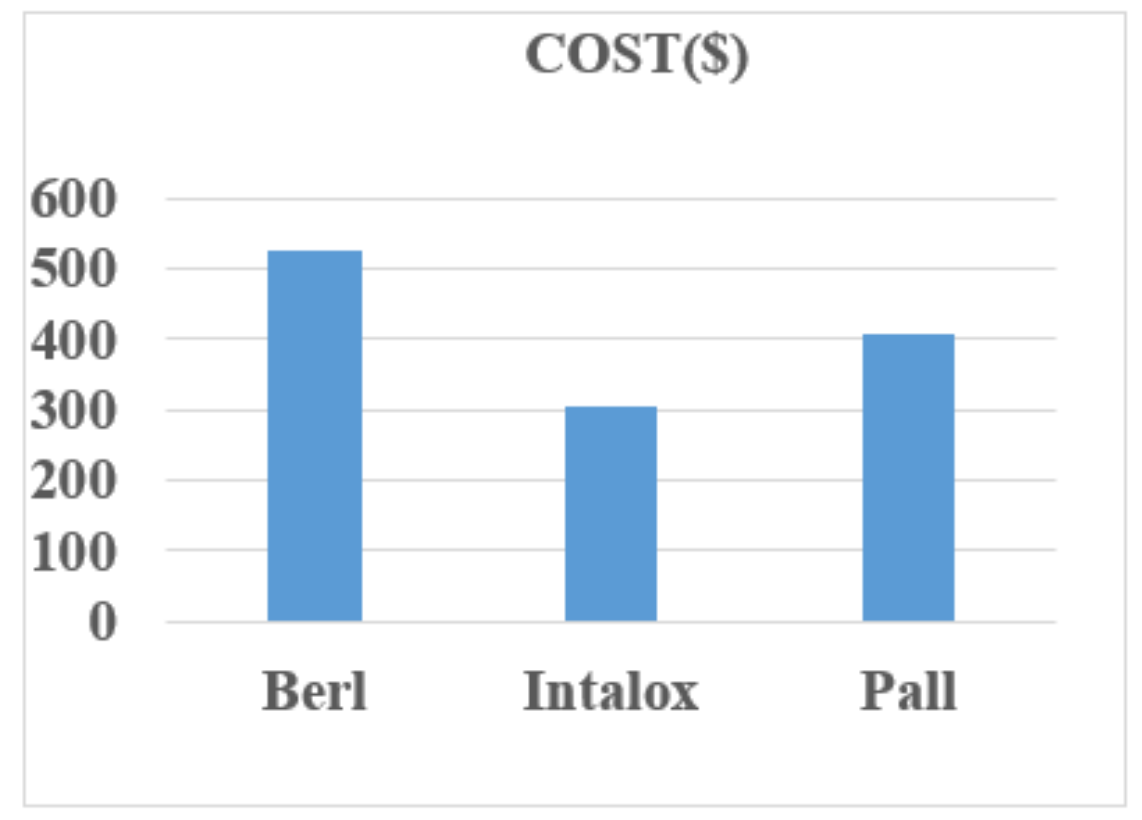

Figure 1. Cost of various packing materials

The results obtained from dual packing (obtained by combining two types of packing) are shown in Figure 2. It was revealed that the best combination is the one resulting from the use of Intalox-Pall. The cost of packing using these two materials is $1 \$ 339$. This value is fall between the costs of Intalox and Pall which are $\backslash \$ 304$ and $\backslash \$ 407$, respectively. The most expensive one is the combination of Berl-Pall followed by Intalox- Berl. The cost of multiple packing was also evaluated to see the synergy between the three types of packings. The results obtained from the cost of these multiple arrangement is $\backslash \$ 412$. Clearly, this cost is higher than what was obtained from dual packing arrangement. 


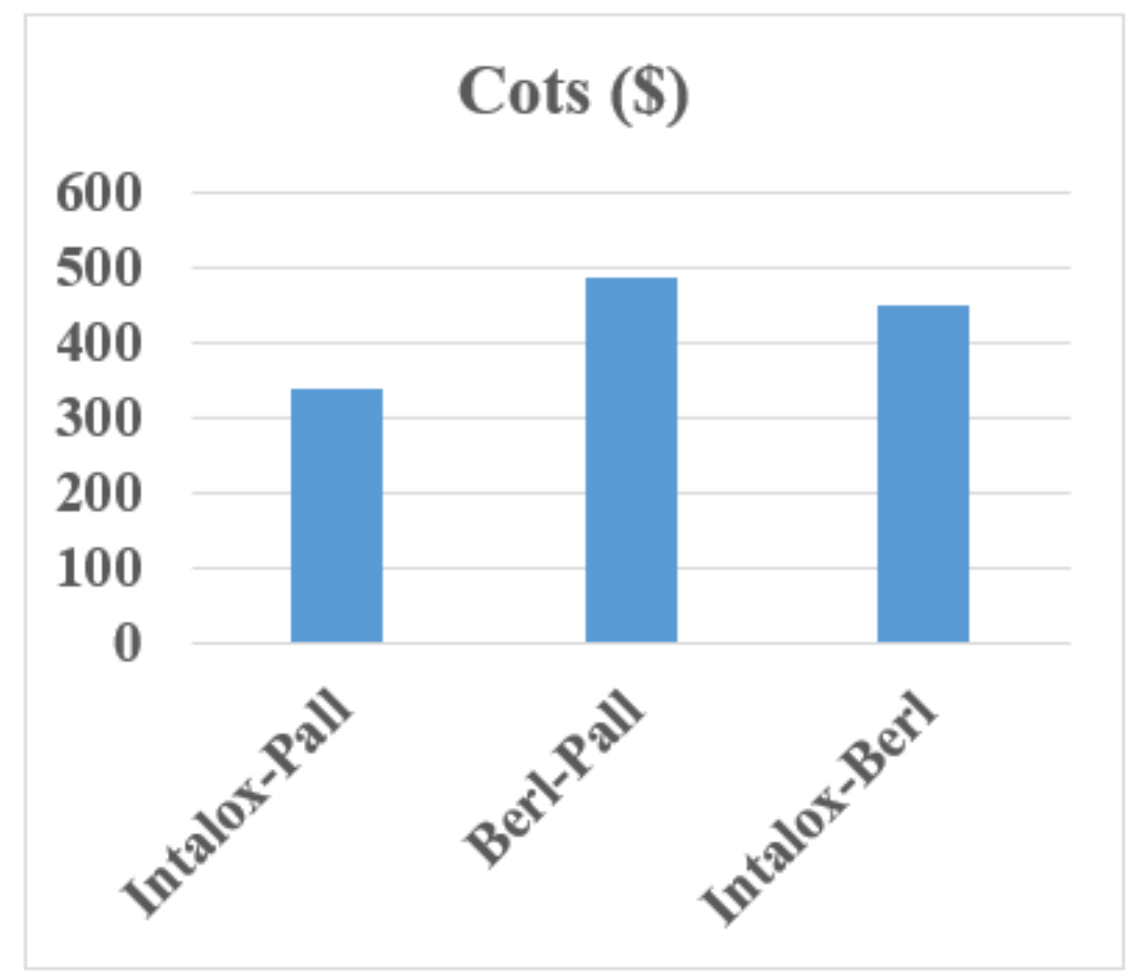

Figure 2. Cost of various packing materials (dual packing arrangement)

Apart from the cost of packing, there are other important factors that needs to be considered. For example, distillation process intensification. One of the way by which the intensification of a process can be achieved is by decreasing the size of the equipment or the plant. Therefore, synergistic effect the multiple packing on the size of the column was also evaluated. The process intensification was evaluated in terms of the column packed height. The results obtained is displayed in the figures below. Figure 3 showed the results of the section height that is needed for three different types of column internals when used individually. The Berl and Intalox were observed to have the lowest height of $3.696 \mathrm{~m}$. As expected, the combination of the two Packings (Intalox-Berl) has the same height $(3.696 \mathrm{~m})$ as when used individually (Figure 3 and Figure 4).

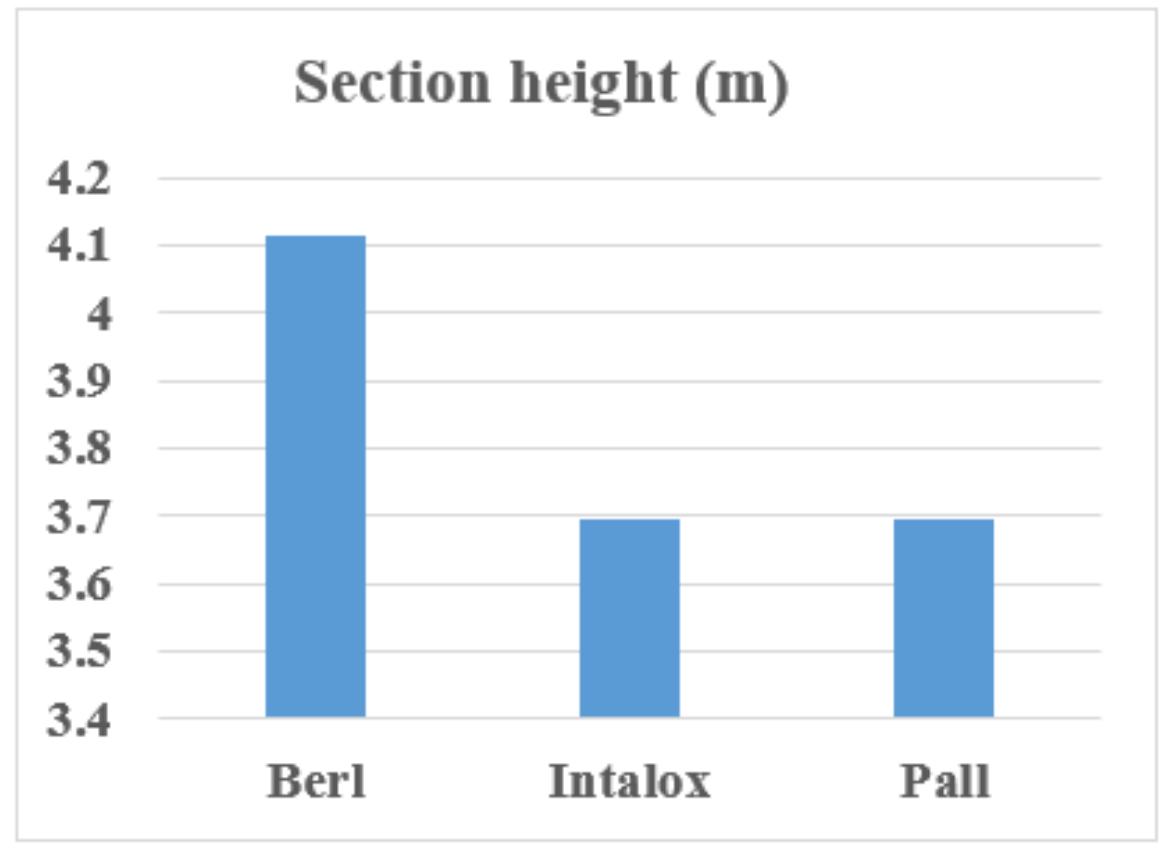




\section{Journal of Student Research}

Figure 3. Section height of various packing materials (Single packing arrangement)

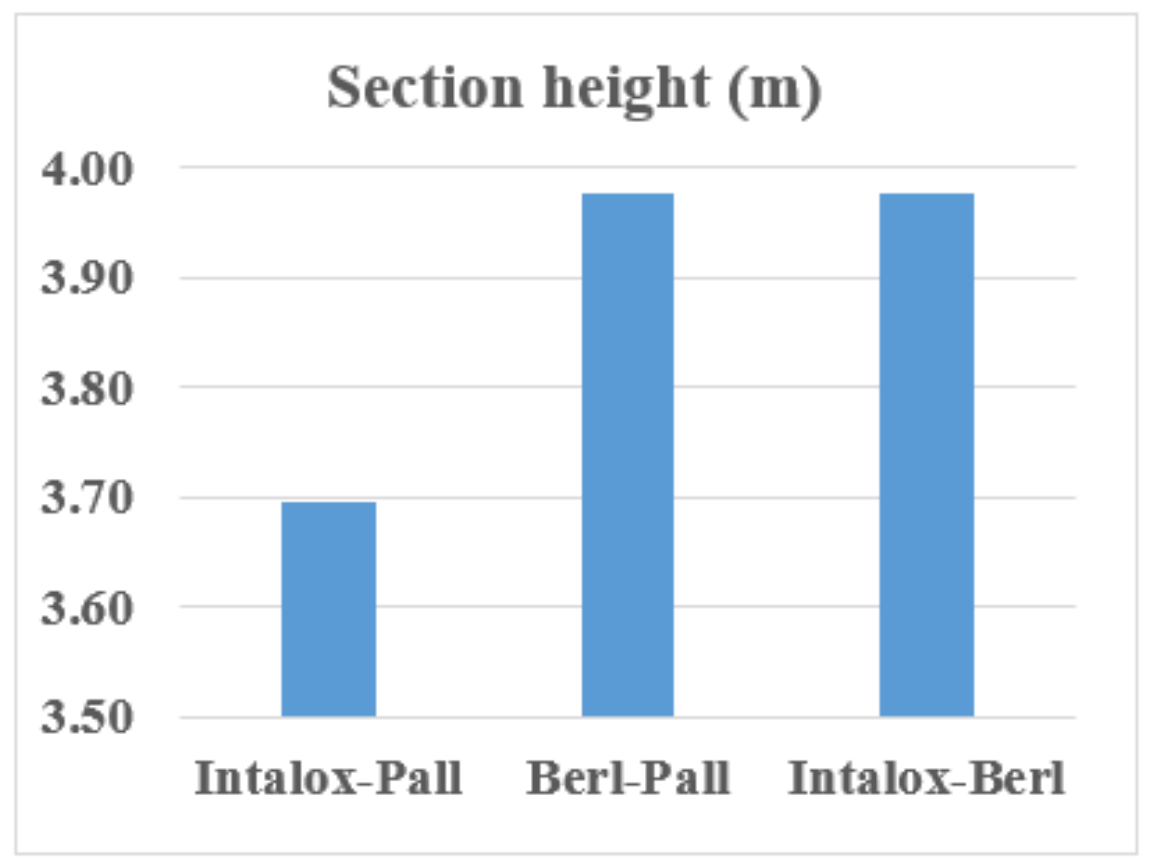

Figure 4. Section height of various packing materials (dual packing arrangement)

One of the important factors that affect the operation of distillation column is the vapour flow condition. Adverse flow condition (either excessive or too low) can cause many challenges. An example of this challenge is flooding. Flooding causes liquid to be entrained in the vapour up the column and it causes increased pressure from excessive vapour. It determines the maximum flow allowed, thus column capacity. Therefore, maximum capacity of the column may be severely reduced by flooding which can result in a significant decrease in separation efficiency. In this study, the effect of multiple packing on separation efficiency of the column was investigated in terms of flooding. The results of the performance of the column using single and dual arrangements of packing internals are shown in the figures below (Figure 5 and Figure 6).

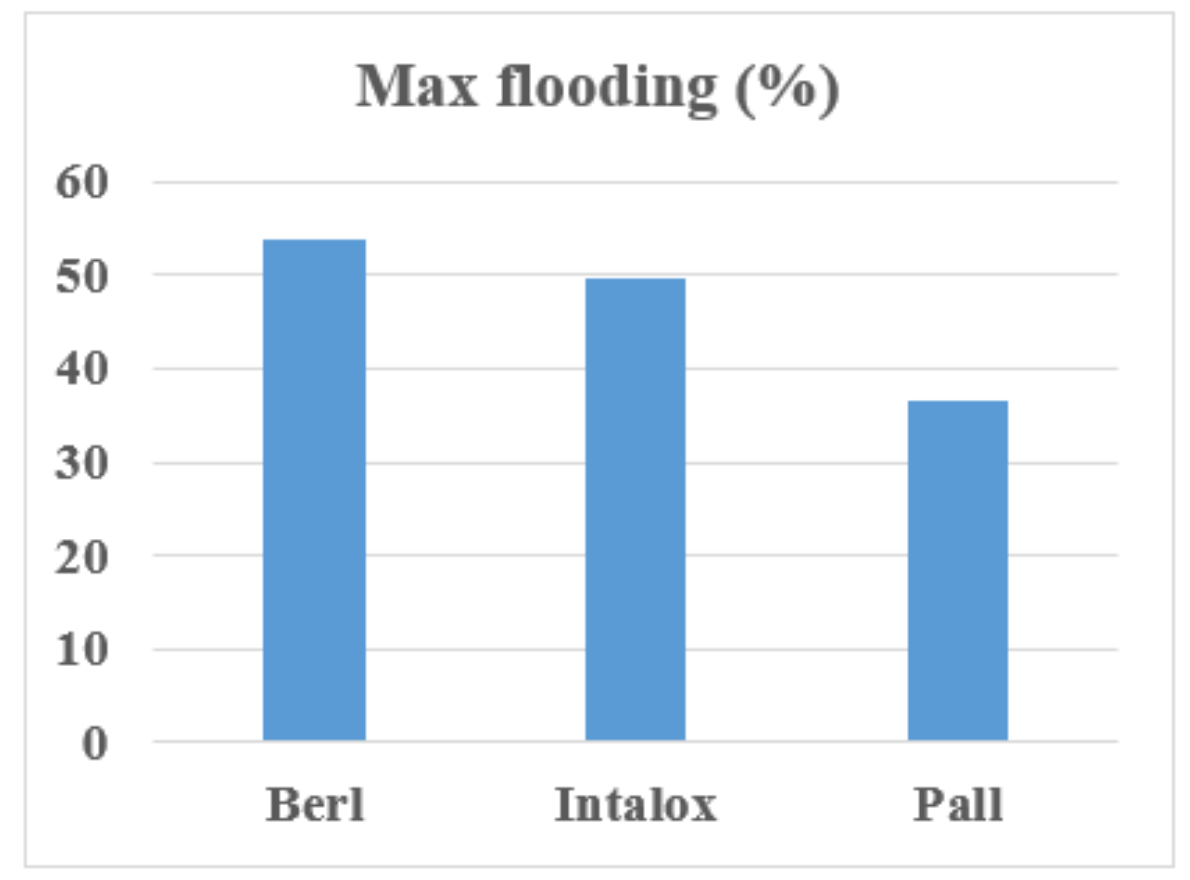


Figure 5. Max Flooding of various packing materials (single packing arrangement)

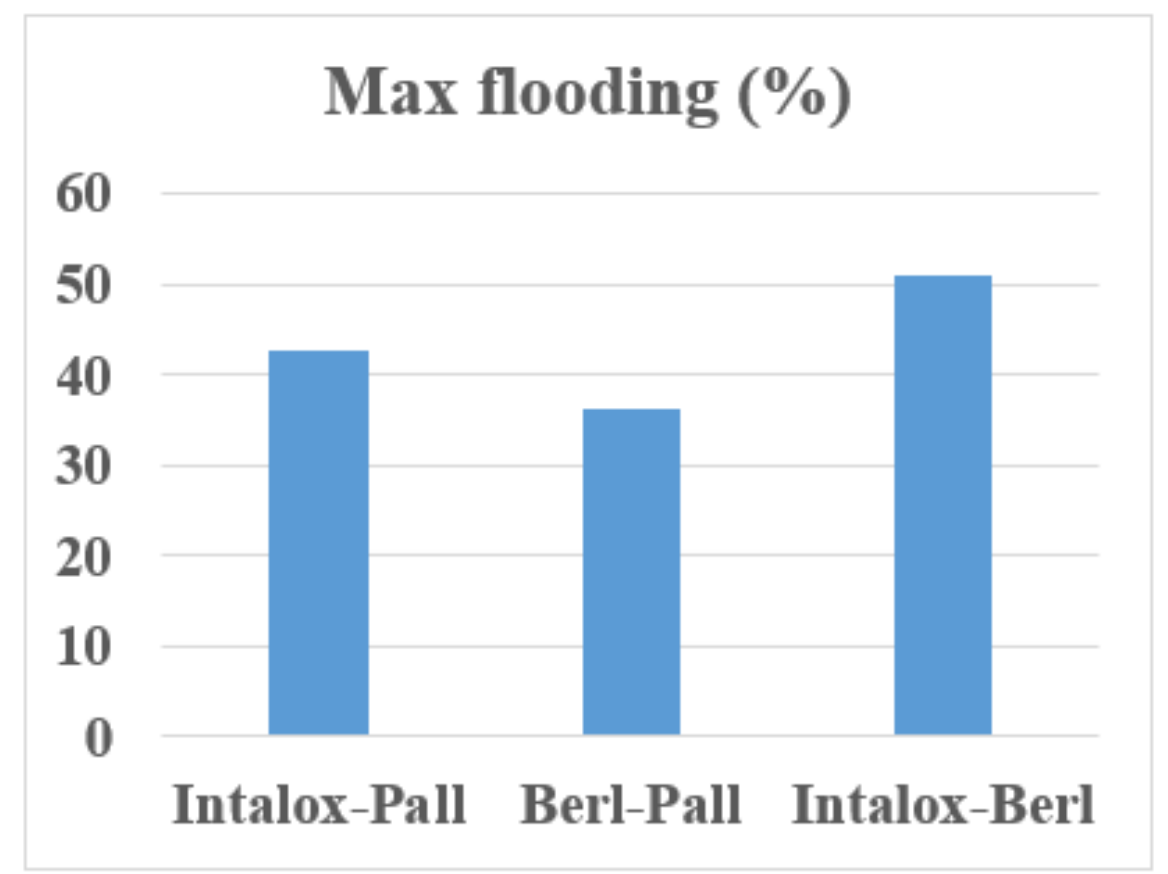

Figure 6. Average Max Flooding of various packing materials (dual packing arrangement)

\section{Conclusion}

The synergistic effect of multiple packing (Berl, Intalox and Pall) in separating binary mixture of pentane and hexane was investigated. The effect of dual and multiple packing arrangements on performance factors such as the cost of packing, the section height, maximum flooding and the mass of packing were investigated. It was observed that dual-packing arrangement can be used to reduce the cost of column and improve the performance of its operation. In using dual arrangement to design column with lower cost, the Berl should not be arranged with the Intalox. The cheapest column could be obtained using a dual arrangement of Intalox and Pall. Similarly, the best process intensification can be obtained by using a dual arrangement of Intalox and Pall because the have the lowest packed diameter. The section height achieved by combining these two packing types is $3.69 \mathrm{~m}$ as compared to the $4.115 \mathrm{~m}$ obtained by using a single arrangement of Berl. On the other hand, the synergistic effect of the dual arrangement resulted in a slight drop in the maximum column capacity. The maximum flooding reduced from $53.7 \%$ for a single arrangement using Berl to $50.85 \%$ using Intalox-Berl. This is equivalent to $5.3 \%$ reduction. On a general note, the use of dual and multiple packing arrangement is found to be beneficial in reducing the cost of column fabrication and increasing the column separation efficiency. It is recommended that further research should be carried out on the effect of these arrangement on other factors such as feed conditions, and reflux conditions. Future work on the use of multiple packing for the separation of multicomponent mixtures is also recommended.

\section{References}

Adewole, J. K. (2009). Computer simulation of multiple packings distillation column. Obafemi Awolowo University.

Gregersen, E. (2016). Distillation. In Encyclopœedia Britannica. Retrieved from https://www.britannica.com/science/distillation 
Jin, Y., Ruan, X., Cheng, X., \& Lü, Q. (2011). Bioresource Technology Liquefaction of lignin by polyethyleneglycol and glycerol. Bioresource Technology, 102(3), 3581-3583.

https://doi.org/10.1016/j.biortech.2010.10.050

Moran, S. (2017). Chapter 22 - Distillation Columns and Towers (S. B. T.-P. P. L. (Second E. Moran, Ed.). https://doi.org/https://doi.org/10.1016/B978-0-12-803355-5.00022-6

Olujić, Ž. (2014). Chapter 1 - Types of Distillation Column Internals (A. Górak \& Ž. B. T.-D. Olujić, Eds.). https://doi.org/https://doi.org/10.1016/B978-0-12-386878-7.00001-2

Sölken, W. (2008). What is a Distillation Column? 